\title{
Effect of Nutrition Education and Counseling Training on Pediatric Residents' Knowledge and Counseling Practices and on Caregivers' Knowledge and Complementary Feeding Practices
}

\author{
Edilberto B. Garcia, Jr.
}

Section of General Pediatrics, Department of Pediatrics, College of Medicine and Philippine General Hospital, University of the Philppines Manila

\begin{abstract}
Objectives. This study aims to determine the effect of nutrition education and counseling training on complementary feeding, on the knowledge and counseling practices of pediatric residents and on the knowledge and feeding practices of caregivers.

Methods. Twenty (20) pediatric residents and 60 caregiver-infant pairs were purposively selected from the outpatient department of a tertiary care hospital. The pediatric residents attended a sixhour nutrition education and counseling training on complementary feeding, which serves as the intervention. A pretest and post-test interview schedule was used to obtain nutrition knowledge and self-reported counseling practices of residents, and nutrition knowledge and feeding practices of caregivers. Nutrition counseling sessions of the residents were video-taped and evaluated. Paired t-test was used to compare pre-test and post-test scores of residents and caregivers before and after the residents' training.
\end{abstract}

Results. Among the residents, statistically significant increases were observed in (a) knowledge scores, 4.7 points $(95 \% \mathrm{Cl} 3.28$ 6.12) $(p=0.0000)$, (b) self-reported practice on complementary feeding, 4.05 points $(95 \% \mathrm{Cl} 0.6-7.5)(p=0.0238)$, and (c) counseling skills, 1.85 points $(95 \% \mathrm{Cl} 1.06-2.64)(p=0.0001)$. The caregivers' knowledge scores increased significantly by 1.15 points $(95 \% \mathrm{Cl} 0.76-1.54)(p=0.0000)$, while the self-reported practice score on complementary feeding decreased by 0.25 points $(95 \% \mathrm{Cl}-1.63-1.13)(p=0.71)$ although this was not statistically significant.

Conclusions. Nutrition education and counseling training on complementary feeding among pediatric residents significantly improved their personal knowledge and counseling practices as well as the knowledge of caregivers. The caregivers' feeding

Presented as a poster at the 13th Asian Conference on Diarrheal Disease and Nutrition, January 10-12, 2012, Taal Vista Hotel, Tagaytay, Philippines.

Corresponding author: Edilberto B. Garcia, Jr., MD, MSPH (Nutrition) Department of Pediatrics

Philippine General Hospital

University of the Philippines Manila

Taft Avenue, Ermita , Manila 1000 Philippines

Telephone: +6325240892

Email: boyinggarcia@gmail.com practices remained the same from baseline to two weeks after the consultation.

Recommendations. An experimental design and longer time for follow-up among caregiver is recommended to control confounders and document the stages of behavior change in feeding practices, respectively.

Key Words: nutrition, education, counseling, physicians, caregivers

\section{Introduction}

Malnutrition rates increase between ages 6 to 18 months, the period of complementary feeding. It is the period when the "exposure to environmental pathogens is most intense, the likelihood of inadequate nutrient intake most probable, and the emotional trauma of less intimate maternal infant contact most stressful" ${ }^{1} \quad$ Identifying approaches and intervention to reduce the prevalence of malnutrition during this critical period is a priority in developing country like the Philippines.

Intervention programmes to promote behavior change in child feeding practices are associated with the use of messages that are clearly understood, feasible to adopt within available resources, and not in contradiction with prevailing beliefs. ${ }^{2}$ The messages used in this study were derived from the Guiding Principles for Feeding NonBreastfed children 6-24 months of age and Guiding Principles for Complementary Feeding of the Breastfed Child. 3,4

Caregivers of target children reached through credible channels who were provided with messages that are consistent and with enough intensity, were motivated to attempt and sustain new behaviors and these resulted in better growth of their infants and young children .2,5-7

Pediatric residents in Philippine Pediatric Society Hospital Accreditation Board (PPS-HAB) training hospitals, are expected to provide nutrition education and counseling to the caregivers of their patients. ${ }^{8}$ They are in a position to commend the caregivers on their good child feeding practices and motivate them to adopt new practices. The nutrition information that the caregiver will gain from the clinic consult may be influenced by the knowledge and counseling skills of the pediatric residents. 
Several studies have shown that nutrition counseling training can cause change in counseling behavior among physicians and improvement in caregivers' knowledge acquisition which can positively result in increased weight gain in pediatric patients. ${ }^{6,9,10}$ However, there is a dearth of information on the baseline knowledge and nutrition counseling practices of physicians, particularly among pediatric residents in training. This study was the first attempt to have a nutrition education and counseling training among pediatric residents in the Philippines and to document its effect on their knowledge and counseling content/skills as well as the caregivers' knowledge and practices on complementary feeding.

The general objective of this study was to determine the effect of nutrition education and counseling training on the knowledge and counseling practices of pediatric residents and on the knowledge and feeding practices of caregivers of 6-24 month-old infants seen at the outpatient department of a tertiary hospital. Specifically, after the nutrition education and counseling training of the residents, this study sought to attain the following: (1) describe the changes in knowledge on complementary feeding among residents; (2) describe the changes in self-reported and observed nutrition counseling practices (content/skills) of residents; and (3) describe the changes in knowledge and complementary feeding practices of caregivers after being counseled by the residents.

\section{Methods}

\section{Study Design and Research Setting}

The study used a non-experimental One Group Pre-test and Post-test design, conducted in the outpatient department of an urban tertiary care hospital from May to June 2011 and approved by the ethical review board of the institution.

\section{Subjects}

Two groups of subjects were included in the study: (1) pediatric residents who saw patients at the outpatient clinic and who have attended the six-hour nutrition education and counseling training sessions; and (2) caregivers of 6-24 month-old infants who sought consult during the study period.

The following subjects were excluded from the study: (1) pediatric residents who failed to attend or complete the six-hour nutrition education and counseling training sessions, failed to accomplish any part of the questionnaire and who were not able to hold clinic consultations; and (2) caregivers who were unable to complete the face-to-face interview before or after the consultation and those who were not able to follow-up after two weeks.

The following formula was used to determine the number of pediatric residents and caregivers to be included in the study: $\quad \mathrm{n}=\left[(\mathrm{Z} \alpha-\mathrm{Z} \beta) \sigma / \mu_{1}-\mu_{0}\right]$
The computed number of pediatric residents needed was 15 but to address the issue of possible drop-outs, 20 residents were enrolled in the study. The following criteria were used: baseline knowledge of $60 \%$ on complementary feeding, improvement in knowledge of $20 \%$ after the intervention, estimated SD of 4,1 tailed $\alpha$ error $=0.05$ and power $=0.8$.

The computed number of caregivers was 20 but to address the variation in residents' counseling content and skills, three caregivers per resident were included. Thus, a total of 60 caregivers were enrolled in the study.

Informed consent was obtained from each subject prior to the start of the study.

\section{Conduct of the Study}

Figure 1 shows the flow of the study. Each of the pediatric residents was videotaped while doing his continuity clinic consultation. After the clinic consultation, they were made to answer Parts I, II and III of the questionnaire for residents that contained questions on their demographic profile, nutrition knowledge and nutrition counseling practices, respectively. The pediatric residents attended a six-hour nutrition education and nutrition counseling training session. After the session, they were asked to answer Part II of the questionnaire on the nutrition test. In the next continuity clinic, the residents were videotaped during clinic consultations with patients who consented to be part of the study. After the consultation, they were asked to accomplish Part III of the questionnaire on nutrition counseling practices.

The videotaped clinic sessions were reviewed and evaluated by evaluators using the Counseling Skills Checklist. ${ }^{11}$ They were blinded to the scoring of the other, to measure the degree of variability or concordance between them, and practice cases were discussed until concordance and consistency were achieved. At least two of the evaluators should agree that there was performance of a particular counseling skill.

A group of caregivers became part of the postintervention group. They were made to answer before the clinic consultation to answer Part I and Part II of the Caregivers' Questionnaire, that contains questions on demographic and nutrition knowledge, respectively. After consultation with the pediatric residents, caregivers answered Part II of the questionnaire on Caregivers' Knowledge.

\section{Data Collection}

Three data collection instruments were used, two for the residents and one for the caregivers. The residents' selfadministered questionnaire, which included demographic profile, was used to assess their knowledge on complementary feeding, nutrition pactices and counseling practices, whereas the counseling checklist was used by the 


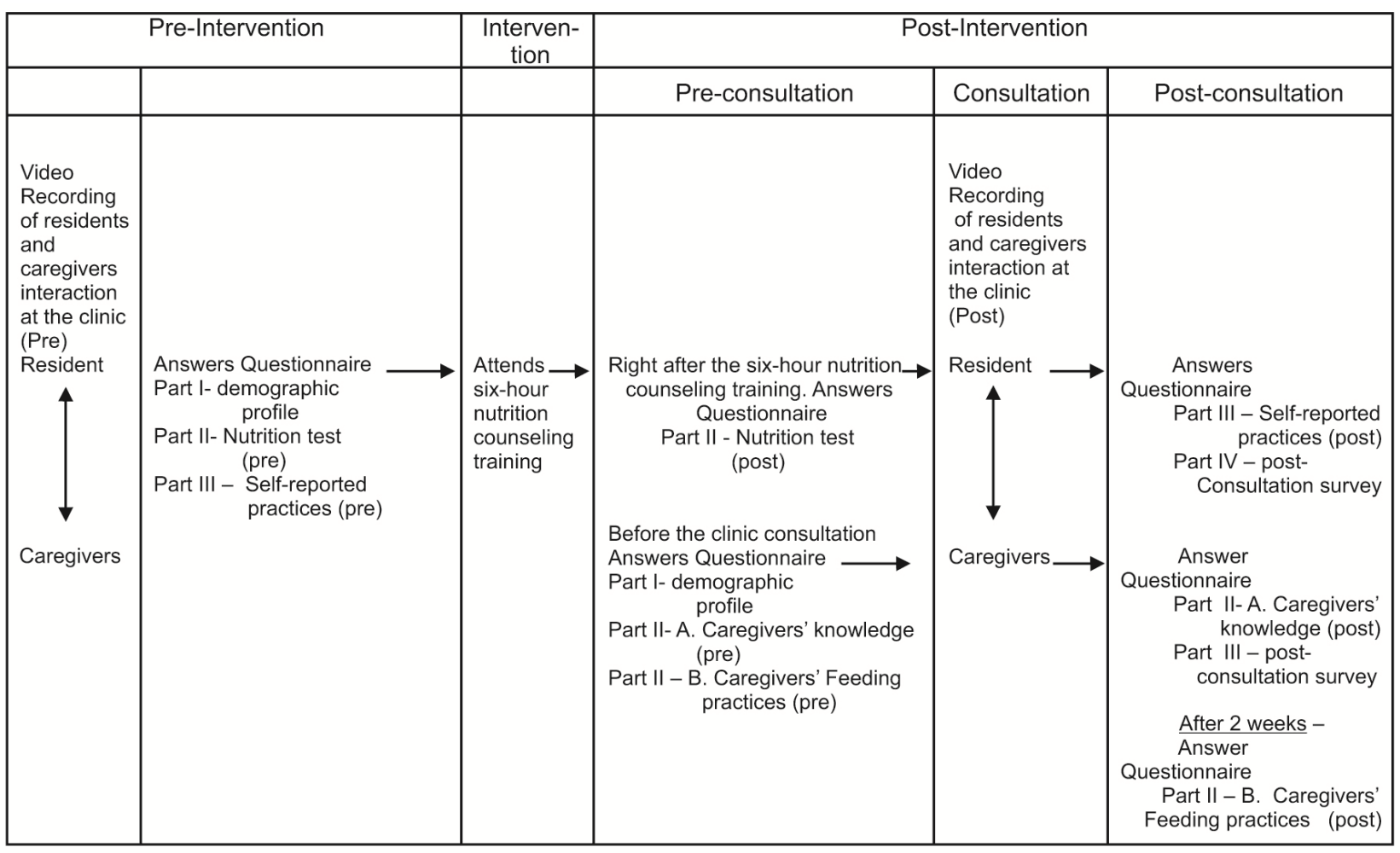

Figure 1. Flow of the study

evaluators to assess the presence or absence of a particular counseling skill of the residents. The caregivers' questionnaire, which included demographic profile, was administered through face-to-face interview and was used to assess their knowledge and current complementary feeding practices.

\section{Data Gathering Procedure}

Two pediatric consultants were hired as research assistants for data collection and for evaluation of counseling skills. The purpose of the study and details of the study from securing informed consent, review of anthropometric measurements, and practice administration of the structured questionnaire were reviewed and observed.

Questions were formulated such that they were simple and easy to answer. A Filipino translation was also written in the questionnaire. Questions that allow multiple answers were properly labeled.

\section{Data Processing and Data Analysis}

The knowledge score of residents before and after the nutrition session were tabulated. Residents' scores on selfreported breastfeeding and complementary feeding practices and evaluators' scores on the actual residents' counseling skills on two occasions, pre and post-educational session, were tabulated and compared.
Knowledge scores of caregivers prior to well/sick baby consultation were tabulated and compared to their postconsultation scores. Complementary feeding practices of caregivers before the consultation were compared with practices two weeks after the consultation.

Microsoft Excel (Microsoft Office, 2007) and Stata 10 software were used to produce master databases and for data manipulation and descriptive statistics that included means, standard deviations, percentiles, and frequency counts in the presentation of data.

Paired t-test was used to compare the residents' knowledge, self-reported practices, and counseling skills before and after the residents' nutrition counseling training. Caregivers' knowledge and feeding practices before and after the residents' nutrition counseling training were tabulated and compared using paired t-test.

\section{Results}

\section{The Residents}

A total of 20 pediatric residents from the study site participated in the study. Each resident saw three caregivers for a total of 60 caregivers.

The mean age is 28.6 years $(\mathrm{SD}= \pm 1.88$ ) with a median age of 29 years. The youngest was 24 years old while the oldest was 32 years old. Table 1 shows the characteristics of the residents. 
Table 1. Characteristics of the Residents $(\mathrm{N}=20)$

\begin{tabular}{rcc}
\hline Characteristics & $\mathbf{n}$ & $\%$ \\
\hline Gender & & \\
Fale & 4 & $20 \%$ \\
Year Level & 16 & $80 \%$ \\
First Year & 9 & $45 \%$ \\
Second Year & 3 & $15 \%$ \\
Third Year & 8 & $40 \%$ \\
Children $\quad$ With & 2 & $10 \%$ \\
Without & 18 & $90 \%$ \\
Complementary feeding & & \\
Practiced & 4 & $20 \%$ \\
Did not practice & 16 & $80 \%$ \\
\hline
\end{tabular}

The residents' pre-intervention and post-intervention scores on nutrition knowledge, self-reported counseling practice, and counseling skills are shown in Table 2. It was observed that knowledge scores based on the nutrition test increased by 4.7 (95\% CI $3.28-6.12)(\mathrm{p}=0.0000)$ indicating improvement in the level of knowledge from 'poor' to 'good'. Their self-reported complementary feeding practices also improved by 4.05 points ( $95 \%$ CI $0.6-7.5)$ ( $p=0.0238)$. Similarly their counseling skills as observed by the evaluators also improved by 1.85 points ( $95 \%$ CI $1.06-2.64$ ) $(p=0.0001)$. The increases in scores in the three areas were statistically significant.

\section{The Caregivers}

The age of caregivers ranged from 19 to 50 years old with a mean of 30.73 years $(S D= \pm 6.97)$ and a median age of 27 years. Table 3 shows the characteristics of the 60 caregivers, two of whom were males while 58 were females. A high $95 \%$ were mothers. More than half (64\%) were either college graduates or undergraduates while the $36 \%$ were either high school graduates or undergraduates. A high percentage $(75 \%)$ of caregivers was unemployed. Since most of the caregivers stayed at home, $90 \%$ spent more than nine hours taking care of their infants.

The caregivers' pre-intervention and post-intervention scores on knowledge and self-reported complementary feeding counseling practices are shown in Table 4. Their knowledge scores based on nutrition test increased by 1.15 (95\% CI $0.76-1.54)(\mathrm{p}=0.0000)$, the difference of which is statistically significant. The level of knowledge improved from 'poor' to 'good'. The caregivers' self-reported practices score on complementary feeding decreased by 0.25 (95\% CI $1.63-1.13)(p=0.71)$ but this difference was not statistically significant.
Table 3. Characteristics of the Caregivers $(\mathrm{N}=60)$

\begin{tabular}{|c|c|c|}
\hline Variable & $\mathbf{n}$ & $\%$ \\
\hline \multicolumn{3}{|l|}{ Gender } \\
\hline male & 2 & 3 \\
\hline female & 58 & 97 \\
\hline \multicolumn{3}{|l|}{ Relation to Infants } \\
\hline mother & 57 & 95 \\
\hline father & 2 & 3 \\
\hline aunt & 1 & 2 \\
\hline \multicolumn{3}{|l|}{ Highest Education } \\
\hline High School undergraduate & 9 & 15 \\
\hline High School graduate & 13 & 21 \\
\hline College undergraduate & 19 & 32 \\
\hline College graduate & 19 & 32 \\
\hline \multicolumn{3}{|l|}{ Occupation } \\
\hline Unemployed & 45 & 75 \\
\hline beautician & 2 & 3.3 \\
\hline laundrywoman & 1 & 1.6 \\
\hline secretary & 2 & 3.3 \\
\hline clerk & 5 & 8.3 \\
\hline tutor & 1 & 1.6 \\
\hline govt. employee & 1 & 1.6 \\
\hline waitress & 1 & 1.6 \\
\hline cook & 1 & 1.6 \\
\hline cashier & 1 & 1.6 \\
\hline \multicolumn{3}{|l|}{ Hours spent with child } \\
\hline$</=4$ & 2 & 3 \\
\hline $5-8$ & 4 & 7 \\
\hline$>1=9$ & 54 & 90 \\
\hline
\end{tabular}

\section{Discussion}

This study demonstrates that nutrition counseling training in complementary feeding was effective in increasing the nutrition knowledge $(\mathrm{p}=0.0000)$, improving the self reported counseling practices $(p=0.0238)$ and counseling skills $(p=0001)$ of pediatric residents. Level of knowledge improved from 'poor' to 'good'. However, one cannot be certain that the increase in residents' knowledge is solely the effect of the intervention during the period of the study since there was a three-day interval between the nutrition pretest and posttest. It is possible that the residents may have sought other sources of information to supplement the nutrition counseling training. The same can be said regarding self-reported practices and counseling skills. In terms of the effect of improvement in knowledge and counseling practices of the residents on the caregivers, the study showed that there is a significant improvement only in the caregivers' knowledge $(p=000)$ but has no effect on their feeding practices $(\mathrm{p}=0.71)$. The increase in knowledge on the part of the caregivers can be attributed to the effect of the training the residents received since the nutrition pretest was taken before the clinic consult, and the nutrition posttest was taken immediately after the clinic

Table 2. Pre-intervention and Post-intervention Scores of Residents ( $N=20)$

\begin{tabular}{|c|c|c|c|c|c|c|c|c|}
\hline \multirow{2}{*}{ Parameter ( Maximum score) } & \multicolumn{2}{|c|}{ Pre } & \multicolumn{2}{|c|}{ Post } & \multirow{2}{*}{ Diff } & \multicolumn{2}{|c|}{$(95 \% \mathrm{CI})$} & \multirow[b]{2}{*}{$\mathrm{p}$} \\
\hline & Mean & SD & Mean & SD & & Lower Limit & Upper Limit & \\
\hline Knowledge (20) & 9.75 & 1.52 & 14.45 & 2.52 & 4.7 & 3.28 & 6.12 & 0 \\
\hline Self-reported practice (52) & 37.2 & 7.16 & 41.25 & 5.84 & 4.05 & 0.6 & 7.5 & 0.0238 \\
\hline Counseling skills (8) & 4.65 & 1.39 & 6.5 & 0.83 & 1.85 & 1.06 & 2.64 & 0.0001 \\
\hline
\end{tabular}


Table 4. Pre-intervention and Post-intervention Scores of Caregivers $(\mathrm{N}=60)$

\begin{tabular}{|c|c|c|c|c|c|c|c|c|}
\hline \multirow{2}{*}{ Parameter ( Maximum score) } & \multicolumn{2}{|c|}{ Pre } & \multicolumn{2}{|c|}{ Post } & \multirow{2}{*}{ Diff } & \multicolumn{2}{|c|}{$(95 \% \mathrm{CI})$} & \multirow[b]{2}{*}{$\mathrm{p}$} \\
\hline & Mean & SD & Mean & SD & & Lower Limit & Upper Limit & \\
\hline Knowledge (20) & 5.9 & 1.272 & 7.05 & 1.048 & 1.15 & 0.76 & 1.54 & 0 \\
\hline Self-reported practice $(52)$ & 57.93 & 4.25 & 57.68 & 4.9 & -0.25 & -1.63 & 1.13 & 0.71 \\
\hline
\end{tabular}

consult. It can be assumed further that the source of the new information was the resident. The findings of no change in the caregivers' feeding practices can be explained by the short interval between pre-intervention assessment and post-intervention assessment.

This is the first local study that assessed complementary feeding knowledge and counseling practices of pediatric residents in an outpatient setting. The low pre-intervention nutrition scores among pediatric residents indicated that there is low level of knowledge on one of the basic nutrition topics in pediatrics which is complementary feeding. This is similar to the results of other studies. ${ }^{12-15}$ The present study did not look into the possible causes of knowledge inadequacy such as: (1) inadequate nutrition education received during undergraduate medical training; (2) inability to recall nutrition information received during their medical years; or (3) the lack of emphasis on nutrition topics on residency core competencies which were elucidated in previous studies.16-19 The significant increase in nutrition scores of pediatric residents after the nutrition counseling training demonstrates the positive effect of the intervention in increasing nutrition knowledge of the residents in this study. This is similar to the results of other studies where the nutrition knowledge of physicians and health workers improved with nutrition counseling training.9,10,20

An experimental design using two groups - control and intervention groups - would have made the results of the study more valid. The unavailability of another pediatric outpatient department which has almost the same characteristics as the caregivers in the present study and the limited number of pediatric residents in the study site, made the author use the non-experimental pretest and posttest design. The use of the pretest-posttest design may have posed testing threat to internal validity. Repeatedly measuring the participants may lead to bias. Participants may remember the correct answers or may be conditioned to know that they are being tested. ${ }^{21}$ However, the correct answers to the questions were not provided, and it is unlikely that the residents would have looked up the answers to the questions after the pretest. Therefore, this potential threat to internal validity was not likely to have a significant influence on the demonstrated positive effect. In this study, the interval between nutrition pretest and posttest was three days. Nonetheless, the results showed that not all residents have increased post-intervention knowledge score which can mean that in some residents there might be a loss or "decay" in information.
The nutrition knowledge of physicians upon entering the pediatric residency training is assumed to be comparable because of the common curriculum among Philippine medical schools. Once accepted into a pediatric training program in Philippine Pediatric Society - Hospital Accreditation Board (PPS-HAB) accredited hospitals, pediatric residents go through the same core curriculum set by the Philippine Pediatric Society, Inc. ${ }^{22}$ At present, there is no structured nutrition counseling course in the core curriculum of the PPS. One can therefore generalize, based on the findings of this study, that a pediatric resident in any PPS-HAB hospital who will undergo nutrition counseling training will have an increase in knowledge in complementary feeding.

The present study also showed that counseling training on complementary feeding could significantly increase the self-reported counseling practices of the pediatric residents. The key messages in complementary feeding were reviewed and visual aids were provided to the residents during counseling sessions. Similar studies, wherein an observer records the number of messages delivered between those who underwent training in counseling and those who did not, have shown that those who had training gave $4 \mathrm{x}$ more number of messages recalled compared to those who had no training. ${ }^{9,10}$

The observed improvement in listening and building confidence skills after the nutrition counseling training is consistent with findings in other studies that used the structured module 'IMCI counseling skills'.9,10 However, another study using structured module 'Infant and young child feeding counseling: an integrated course' showed there were minimal gains in counseling skills. ${ }^{20}$ This might be due to the fact that IMCI counseling skills focused primarily on a specific topic, complementary feeding, while the former focused on varied topics such as breastfeeding, HIV, and infant and young child feeding, and complementary feeding.

The nutrition counseling training program used in this study, adapted from the WHO counseling training course for complementary feeding for health workers, has several characteristics that may explain the increase in knowledge and counseling practices of pediatric residents: (1) key messages were listed under the guiding principles and the scientific rationale for each of the recommended practices, and (2) listening and building confidence skills to promote rapport and effective communication is presented as case scenarios where participants actively participate..$^{9,11}$ 
The increase in knowledge and improvement in the content and counseling skills of pediatric residents brought about by the training translated into increase in knowledge among the caregivers. The result is similar to other studies that showed mothers being able to recall information provided by trained health workers. ${ }^{9,10}$ Knowledge on appropriate feeding practices can also be improved by health care providers during clinic visit, both well baby and sick consultation. ${ }^{23}$ In the present study, both well and sick infants have been included since the training involves a key message pertaining to how and what to feed a sick child. The sick child consultation is also considered a 'teachable moment', a time period in which caregivers seek information regarding the illness and are ready to accept advice on what to do. ${ }^{24}$

One of the factors that might have influenced the increase in knowledge of the caregivers is their educational attainment. Since most of the caregivers are college graduates and undergraduates, they were able to comprehend the information given by the pediatric residents. The education level of caregivers plays a vital role in increasing receptiveness to nutritional requirements of their infants. ${ }^{25}$ Nutrition education programs using a communication mix of channels with repeated reinforcement can bring about improvement not only in awareness but also in infant feeding practices. ${ }^{26}$

In this study, the increased knowledge among the caregivers did not translate into improvement in complementary feeding practices. The short time interval two-weeks to one-month - may not be adequate to bring about behavioral change. According to the Transtheoretical (Stages of change) model, the following six steps comprise the complex process individuals undergo to change their habits and behaviors and integrate changes into their lives: precontemplation, contemplation, preparation, action, and maintenance and termination. The interval time from precontemplation to the action stage is around six months. ${ }^{27}$ In LINKAGES project, "Behavior Change Communication for Improved Infant Feeding", an individual has to go through the following stages of change and interventions to encourage change: 1) Never heard about it - Gave information, 2) Heard about it - Negotiated / Encouraged. The next two steps were beyond the scope of the study: 3) Trying it out - Praise, discuss benefits and 4) Continuing to do it - Support..$^{28}$ The need for follow-up sessions or targeted nutrition counseling should be looked into. The targeted nutrition counseling employed in the study discussed only one or two concerns raised by the caregivers during the consult.

Study results support the need for a structured nutrition education and counseling training among pediatric residents that increase their knowledge base and improve their counseling skills, which will hopefully translate to increased knowledge and improved feeding practices of the caregivers.

\section{Conclusions}

One intervention strategy to prevent child malnutrition and mortality is the promotion of appropriate feeding practices through nutrition counseling. Barriers to nutrition counseling were expounded in previous studies and these include lack of knowledge and training on the part of the health care provider. Nutrition education and counseling training on complementary feeding among pediatric residents improved significantly their nutrition knowledge and counseling practices as well as the nutrition knowledge of caregivers. But the improved nutrition knowledge of the caregivers did not show any significant improvement on their feeding practices during the two weeks to one-month interval.

\section{Recommendations}

An experimental design using a control group and randomization method would help control for confounders like other possible sources of information that may have influenced the residents.

A longer time for follow-up among caregivers may be employed to document the stages of behavior change in feeding practices which may take up to six months.

Enhancement of nutirion counseling training on complementary feeding should be routinely adopted in the curriculum of undergraduate medical students and of pediatric residents to address the lack of knowledge and confidence in giving nutrition counseling.

\section{References}

1. Underwood BA. Weaning practices in deprived environments: the weaning dilemma. Pediatrics. 1985; 75(1 Pt 2):194-8.

2. Allen LH, Gillespie SR. What works? A review of the efficacy and effectiveness of nutrition interventions, ACC/SCN: Geneva in collaboration with the Asian Development Bank, Manila, 2001.

3. World Health Organization. Guiding principles for feeding nonbreastfed children 6-24 months of age. World Health Organization. Geneva, Switzerland, 2005.

4. PAHO/WHO. Guiding Principles for Complementary Feeding of the Breastfed Child. Division of Health Promotion and Protection. Food and Nutrition Program. Pan American Health Organization/World Health Organization. Washington/Geneva, 2003.

5. WHO/UNICEF. Complementary feeding of young children in developing countries: a review of current scientific knowledge. Geneva: World Health Organization, WHO/NUT/98.1, 1998.

6. Santos I, Victora CG, Martines J, et al. Nutrition counseling increases weight gain among Brazilian children. J Nutr. 2001; 131(11):2866-73.

7. Saha KK, Frongillo EA, Alam DS, Arifeen SE, Persson LA, Rasmussen KM. Appropriate infant feeding practices result in better growth of infants and young children in rural Bangladesh. Am J Clin Nutr. 2008; 87(6):1852-9.

8. Philippine Pediatric Society Inc. Preventive Pediatrics, 2010.

9. Pelto GH, Santos I, Goncalves H, Victora C, Martines J, Habicht J. Nutrition counseling training changes physician behavior and improves caregiver knowledge acquisition. J Nutr. 2004; 134(2):357-62. 
10. Zaman S, Ashraf RN, Martines J. Training in complementary feeding counseling of healthcare workers and its influence on maternal behaviours and child growth: a cluster-randomized controlled trial in Lahore, Pakistan. J Health Popul Nutr. 2008; 26(2):210-22.

11. World Health Organization. Complementary feeding counseling training Course. World Health Organization. Geneva, Switzerland, 2004.

12. Krause TO, Fox HM. Nutritional knowledge and attitudes of physicians. J Am Diet Assoc. 1977; 70(6):607-9.

13. Temple NJ. Survey of nutrition knowledge of Canadian physicians. J Am Coll Nutr.1999; 18(1):26-9.

14. Al-Numair KS. Nutrition knowledge of primary care physicians in Saudi Arabia. Pakistan Journal of Nutrition. 2004; 3(6):344-7.

15. Uddin MT, Islam MN, Uddin MJ. A survey on knowledge of nutrition of physicians in Bangladesh: evidence from Sylhet data. South East Asian Journal of Medical Education. 2008;2(2):14-7.

16. Hiddink GJ, Hautvast JG, van Woerkum CM, Fieren CJ, van't Hof MA. Nutrition guidance by primary-care physicians: perceived barriers and low involvement. Eur J Clin Nutr. 1995;49(11):842-51.

17. Freed GL, Clark SI, Sorenson J, Lohr JA, Cefalo R, Curtis P. National assessment of physicians' breastfeeding knowledge, attitudes, training, and experience. JAMA.1995; 273(6):472-6.

18. Novick JS. Effect of a nutrition education program on the related Knowledge and behaviors of family practice residents. MS Thesis in Nutrition, The School of Graduate Studies, Department of Family and Consumer Sciences, Indiana State University, Tere Hayte, Indiana, USA, 2000 .

19. Kolasa KM, Rickett K. Barriers to providing nutrition counseling cited by physicians: a survey of primary care practitioners. Nutr Clin Pract. 2010; 25(5):502-9.
20. Bassichetto KC, Rea MF. Infant and young child feeding counseling: an intervention study. J Pediatr (Rio J). 2008; 84(1):75-82.

21. Fraenkel JR, Wallen NE. How to design and evaluate research in education, $7^{\text {th }}$ ed, International Edition. Boston: McGraw-Hill Higher Education; 2010 .

22. Philippine Pediatric Society Inc. Guide to Core Pediatrics. 2008

23. Bhandari N, Mazumder S, Bahl R, et al. Use of multiple opportunities for improving feeding practices in under - twos within child health programmes. Health Policy Plan. 2005; 20(5):328-36.

24. Maccoby N, Romney AK, Adams JS, Maccoby EE. "Critical periods" in seeking and accepting information. In: Paris - Stanford studies in Communication. Stanford, California Institute for Communication Research, Stanford University; 1962:47-57.

25. Liaqat P, Rizvi MA, Qayyum A, Hajra A, Nadia I. Maternal Education and Complementary feeding. Pakistan Journal of Nutrition. 2006; 5(6):563-8.

26. Sethi V, Kashyap S, Sethi V. Infant feeding practices in a relocated slum - a pilot study. Indian Pediatr. 2003; 40(6):579-80.

27. Prochaska JO, Johnson SS, Lee P. The transtheoretical model of behavior change. In: Schumaker S, Schron E, Ockene J, McBee W, eds. The Handbook of Health Behavior Change, $2^{\text {nd }}$ ed. New York, NY: Springer; 1998. pp.

28. LINKAGES project. Behavior Change Communication for Improved Infant Feeding - Training of Trainers for Negotiating Sustainable Behavior Change [Online]. 2004. [cited 2007 May]. Available from http://www.linkagesproject.org/media/publications/Training\%20Modul es/BCCand_IF.pdf.

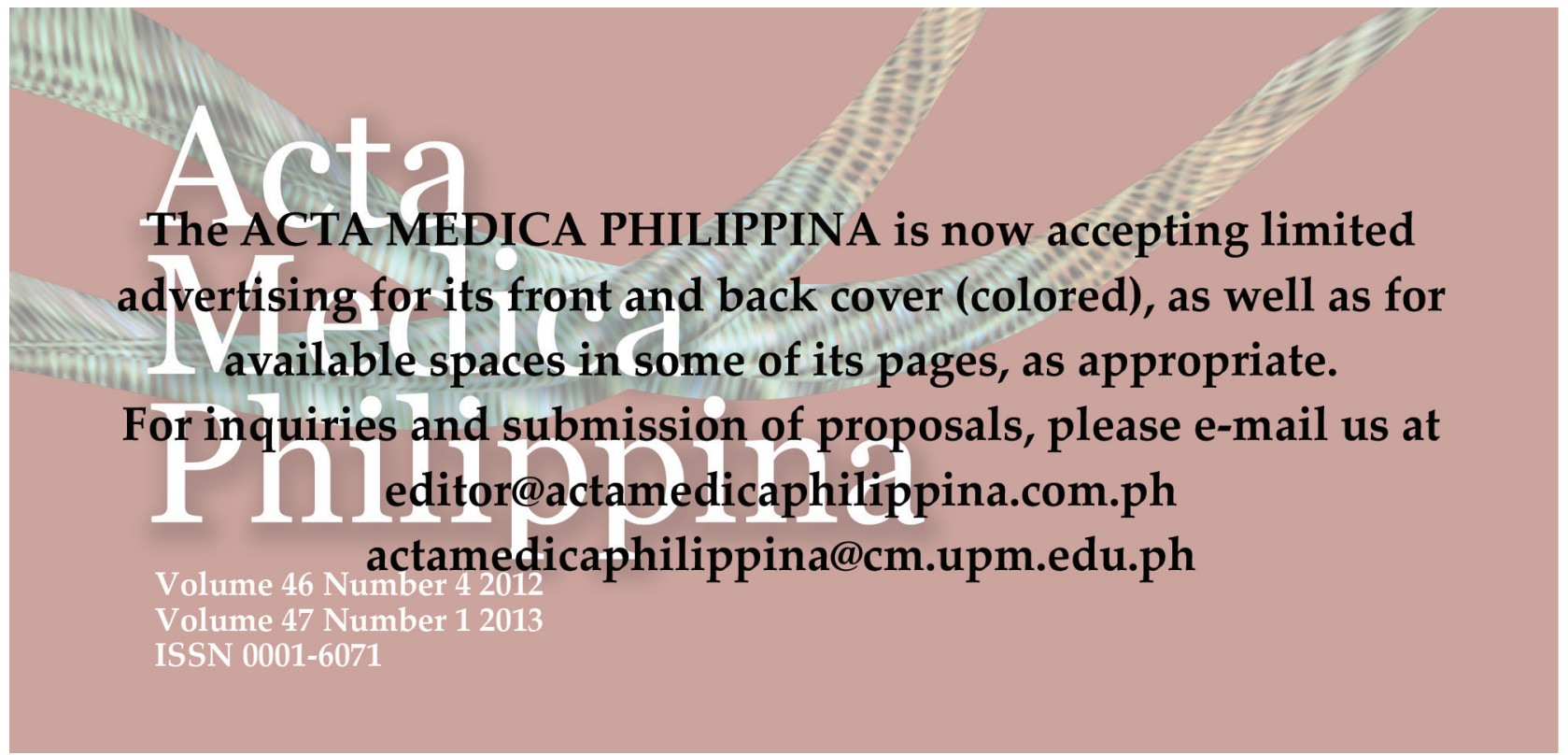

